\title{
Original Article \\ Hepatitis B Vaccine Uptake among Voluntary Blood Donors in Jos: Implication on Blood Safety
}

Zakari A, ${ }^{1}$ Jatau E D, ${ }^{1}$ Ma'an V T, ${ }^{2}$ Rumji M E, ${ }^{3}$ Damulak O D, ${ }^{1}$ Egesie O J. ${ }^{1}$

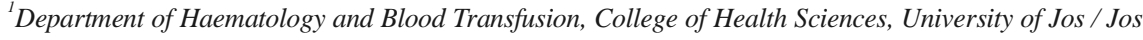
University Teaching Hospital, Jos Nigeria..

${ }^{2}$ Department of Haematology and Blood Transfusion Jos University Teaching Hospital Jos Nigeria

${ }^{3}$ National Blood Transfusion Service North-Central Zone, Jos, Nigeria.

\section{OPEN ACCESS}

*Correspondence Ayuba Zakari, Department of Haematology, College of Health Sciences University of Jos

Tel: +2349023634444

Email: ayubanet@yahoo.com

Specialty section: This article was submitted to Haematology, a section of JRBCS

Received: 31 May 2021 Accepted: 30 June 202 Published: 10 July 202

Citation: Zakari A, Jatau E D, Ma'an VT, Rumji $M$ E, Damulak $O D$ Egesie O J. Hepatitis B Vaccine Uptake among Voluntary Blood

Donors in Jos: Implication on Blood Safety. J Res Bas Clin Sci 2(1):35-41. DOI.10.46912/jrbcs. 92

\section{ABSTRACT}

Hepatitis B virus (HBV) is a transfusion-transmissible pathogen that poses a significant threat to blood safety. The virus' burden is high in the general population and among blood donors in Sub-Saharan Africa, leading to more donor rejection; blood discards, and increased risk of contamination of the blood supply. Hepatitis B Virus is vaccine-preventable; increased burden of infection may suggest a gap in vaccination. The study aimed to assess the level of hepatitis B virus vaccine uptake and identify factors affecting uptake of the vaccine among voluntary non remunerated blood donors (VNRBD) in Jos, Nigeria. A survey was conducted at the National Blood Transfusion Service (NBTS), Jos, among consenting VNRBD aged between 18 and 65 years from October to December 2020 using a structured questionnaire to collect information on vaccination status, socio-demographics and others. Of the 120 VNRBD interviewed, $36.7 \%$ received one or more doses of the HBV vaccine, while the majority (63.3\%) were unvaccinated. Among the unvaccinated donors, $57.9 \%$ were unaware that $\mathrm{HBV}$ has a vaccine, $21.1 \%$ did not know where to get the vaccine, $7.9 \%$ had no time to get vaccinated; $3.9 \%$ believed that there was no need to get vaccinated because they tested negative for the virus, while $9.2 \%$ gave no reason. Our study found a low uptake of HBV vaccine among VNRBD in our environment. We advocate for increased awareness and strong legislation to ensure universal access to the vaccine by Nigerians.

Keywords: Hepatitis B virus, Vaccine uptake, Voluntary non remunerated blood donors, Blood safety

\section{INTRODUCTION}

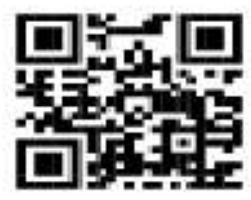

$\mathrm{B}$ lood transfusion service worldwide faces risks from both known and unknown pathogens. ${ }^{1}$ While some of what is known are tested for, a significant threat is posed to transfusion safety from transfusion transmissible pathogens that can exist in a state of latency. ${ }^{2}$ One such pathogen is the Hepatitis B virus (HBV), implicated in

http://jrbc.org 
chronic liver disease and hepatocellular carcinoma. ${ }^{3,4}$ The global burden of HBV is high, posing a significant threat to the availability of safe blood worldwide. ${ }^{5}$ This threat is accentuated in resource-limited countries where frequent disruptions of basic testing kits are experienced in the background of the scarcity of advanced screening methods. ${ }^{5}$ Several studies have documented a high prevalence of HBV among Voluntary non-remunerated Blood Donors (VNRBD) in Sub-Saharan Africa. ${ }^{67,8}$ This high prevalence translates to more blood discards which come at an enormous cost to the regional blood services. ${ }^{6}$ It also heightens the risk of introducing a positive unit into the transfusion chain with its attendant consequences on blood safety. ${ }^{9} 10$ Priority must be given to the vaccination of the population as blood donors are derived from the community. Available literature searched showed a paucity of studies that specifically addressed the status of HBV vaccination of blood donors in our environment. This study aimed to assess the level of hepatitis B virus vaccine uptake, identify factors affecting uptake of the vaccine among VNRBD in Jos, Nigeria and generate baseline data to influence policy decision on blood safety in our environment.

\section{MATERIALSAND METHODS}

\section{Study area}

The study was conducted at the National Blood Transfusion Service (NBTS), North-Central Zone of Nigeria. The NBTS is located in Jos, the capital of Plateau State and serves the blood need of Plateau State and the neighbouring States of Bauchi, Kaduna, Benue, Nasarawa Taraba.

\section{Study design}

This was a cross-sectional facility-based study conducted between October and December 2020. Participants were consenting VNRBD aged $18-65$ years presenting at the regional NBTS for blood donation. As the participants arrived for blood donation, the study objective was explained to them and their consent sought to participate in the study. All the participants gave informed consent and were consecutively recruited until the desired sample size of 120 was attained. A structured questionnaire was used to obtain socio-demographic, HBV immunization history and other information from subjects.

\section{Ethical Approval}

Ethical approval was obtained from the NBTS before the work was carried out. Informed consent was obtained from each subject before enrollment.

\section{Data Analysis}

Data obtained were cleaned, coded and entered into a predesigned excel spreadsheet and subsequently analyzed using the IBM Statistics for windows, version 23.0 (Chicago, IL: IBM Corp). Mean, and Standard deviation were used to summarize normally distributed continuous variable. Chi-square was used to test the associations between categorical variables. Results were presented using tables and charts.

\section{RESULTS}

A total of 120 blood donors were interviewed, of which $86(71.7 \%)$ were males and 34 (28.3\%) females, giving a Male: Female of 2.5:1. They were aged between 18 and 58 years with a mean $( \pm \mathrm{SD})$ of $36.12 \pm 10.22$ years, and a median age of 35 years. The highest number of donors belonged to the age group of 28-37 years. The majority of blood donors were self-employed 41 (34.2\%), others were civil servants; 34 (28.3\%), students; 26 (21.7\%), business; 6 (5.0\%) and security personnel and clergies; (10.8\%). Ninety-six $(80.0 \%)$ of subjects attained tertiary level education, while those with secondary and primary education were $18.3 \%$ and $1.7 \%$, respectively. Sixty-four (53.3\%) of subjects were married and 53 (46.7\%) unmarried (Table 1).

All the subjects (100\%) were voluntary nonremunerated donors. First-time and Repeat donors were 
Table 1. Socio-demographic characteristics of Voluntary

Blood donors in Jos between October and December 2020

\begin{tabular}{lcc}
\hline $\begin{array}{l}\text { Demographic } \\
\text { characteristics }\end{array}$ & Frequency & Percentage \\
\hline Age group & & \\
$18-27$ & 25 & 20.8 \\
$28-37$ & 48 & 40.0 \\
$38-47$ & 26 & 15.8 \\
$48-57$ & 19 & 21.7 \\
$58-67$ & 2 & 1.7 \\
Gender & & \\
Male & 86 & 71.7 \\
Female & 34 & 28.3 \\
Educational level & & \\
Primary & 2 & 1.7 \\
Secondary & 22 & 18.3 \\
Tertiary & 96 & 80.0 \\
Marital status & & \\
Married & 64 & 53.3 \\
Single & 56 & 46.7 \\
Occupation & & \\
Civil servant & 34 & 28.3 \\
Self -employed & 41 & 34.2 \\
Student & 26 & 21.7 \\
Business & 6 & 5.0 \\
Others & 13 & 10.8 \\
\hline
\end{tabular}

First time donor

Repeat donor

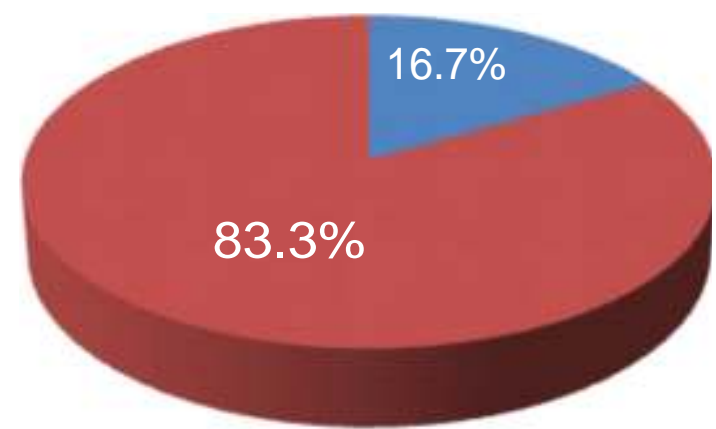

Figure 1. Type of Voluntary blood donors at NBTS Jos, between October and December 2020

Table 2. Frequency of blood donation among Voluntary Blood donors in Jos between October and 2020

\begin{tabular}{lcc}
\hline Grouping & Frequency $(\mathrm{n}=99)$ & Percentage \\
\hline$\leq 10$ & 70 & 70.7 \\
$11-20$ & 19 & 19.2 \\
$>20$ & 10 & 10.1 \\
\hline
\end{tabular}

Table 3. Hepatitis B Vaccination status of voluntary blood donors in Jos between October and December 2020

\begin{tabular}{lcc}
\hline Variables & Frequency & Percentage \\
\hline Vaccination status & 44 & 36.7 \\
Vaccinated & 76 & 63.3 \\
Unvaccinated & & \\
Reasons for not vaccinated (n=76) & 44 & 57.9 \\
Not aware of the vaccine & 16 & 21.1 \\
Don't know where to get the vaccine & 6 & 7.9 \\
No time to get vaccinated & 3 & 3.9 \\
Tested negative & 7 & 9.2 \\
No reason & & 25.8 \\
Completed recommended 3 dos(smong all the participants) n=120 & 31 & 62.1 \\
Completed & & 37.9 \\
Received vaccine (among those that were aware of hepatitis B vaccine) $\mathbf{n = 6 6}$ & 41 & 25 \\
Yes & 25 \\
No & & \\
\hline
\end{tabular}


$16.7 \%$ and $83.3 \%$, respectively (Figure 1).

The frequency of donation by subjects ranged from 2 to 34 times as the time the study was being conducted. The majority of repeat donors (70.7\%) had donated up to ten times. (Table 2).

Subjects who received the vaccine constituted $36.7 \%$, while the majority $(63.6 \%)$ were unvaccinated against the hepatitis B virus. Among the unvaccinated subjects, $44(57.9 \%)$ were unaware that hepatitis B has a vaccine, $16(21.1 \%)$ did not know where to get the vaccine, $3(3.9 \%)$ subjects felt they did not need the vaccine since they tested negative for the virus; 6 (7.9\%) had no time to get vaccinated, while 7 (9.2\%) gave no reason for their unvaccinated status. The majority $(70.5 \%)$ of those that had the vaccine completed the recommended three doses, while the remaining $29.5 \%$ were yet to do so (Table 3 ).

\section{DISCUSSION}

In our study, only $44(36.7 \%)$ of voluntary blood donors received one or more doses of $\mathrm{HBV}$ vaccine, of which $31(70.5 \%)$ completed the recommended three doses of the vaccine that offer protection against HBV. However, the low uptake of vaccination found in our study is higher than that reported by Bonsu et al, ${ }^{11} \mathrm{Abdo}$ et al. ${ }^{12}$ and El-Ghitny et al. ${ }^{13}$ from Ghana, Sudan and Egypt, respectively. The low uptake of HBV vaccine by VBD in this study may reflect that in the general population where donors are derived from. Among medical students, low uptake was reported in Cameroun $(26.05 \%),{ }^{14}$ Kenya $(44.3 \%),{ }^{15}$ and Ghana $(30 \%){ }^{16}$ Among health care personnel, low uptake was reported in Tanzania (33.6\%), ${ }^{17}$ Ethiopia $(27.6 \%)^{18}$ and Enugu, South Eastern Nigeria (14.2\%). ${ }^{19}$ However, higher uptake was found in developed countries such as Italy $(80 \%)^{20}$ and France (88.6\%). ${ }^{21}$ The higher uptake seen in developed countries may be due to enhanced awareness and universal implementation of routine childhood anti $\mathrm{HBV}$ vaccination.

Among the unvaccinated subjects, identified factors affecting vaccine uptake included poor knowledge of the availability of $\mathrm{HBV}$ vaccine (57.9\%), access to the vaccine $(21.1 \%)$, and poor perception of the need for vaccination $(3.9 \%)$. These identified negative factors affecting vaccine uptake can be reduced through targeted dissemination of the right information about the availability of vaccine and where it can be accessed. During pre-donation counselling, information about HBV vaccination should be sought, and donors counselled on the need to get vaccinated to ensure complete protection from the virus. The majority $(83.3 \%)$ of our subjects were repeated donors, with donation frequency ranging from two to thirty-four. Most of them were young and have attained tertiary level education; therefore, commitment to blood donation is done from an informed position. Such blood donors needed to be protected against HBV to guarantee a stable pool of safe VNRBD that can be retained over several years.

The expanded program on immunization (EPI) had been in place in Nigeria for decades. ${ }^{22}$ Hepatitis B vaccine was incorporated as part of the routine childhood immunization in 1990, with the vaccine given at birth, 6 and 14 weeks. ${ }^{22}$ The vaccine is safe and effective. Its introduction led to a decline in the proportion of under-five children chronically infected with the virus from $5 \%$ in the pre-vaccination era to under $1 \%$ in $2019 .^{23}$ The estimated global coverage of the vaccine in 2019 was $43 \%$, while the coverage in Africa was lower $(6 \%) .^{23}$ In Nigeria, a significant proportion of births are done outside the hospital setting, depriving the newborns of the HBV vaccine. ${ }^{24}$ One of the strategies to improve access to vaccines for babies born outside the hospital setting is to educate the traditional birth attendants of the usefulness and availability of the vaccines. Such information can be passed to the mothers, who will be directed to immunization centres for vaccination of the newborns.

As childhood immunization is being strengthened through well-articulated and nationally accepted policies, a well-defined strategy to bring the 
unvaccinated adult population into the vaccine net must be developed. As adults cannot be forced to get vaccinated in contrast to newborns, the concept must be made attractive to them; aggressive and targeted dissemination of information on the benefits of the vaccine will facilitate voluntary acceptance. The right information can be passed to the population at health facilities, places of worship, billboards, health education in schools, print, and electronic media. Hepatitis B is vaccine-preventable; therefore, a high burden of it and other vaccine-preventable infections in any society suggests a gap in vaccination.

The rational use of blood and blood products demands that recipients of blood and products be given only the desired component. ${ }^{25}$ Whole blood, when separated into its various component, can benefit more than one recipient; the transfusion of such components from a donor with occult $\mathrm{HBV}$ puts more than one recipient at risk of HBV infection. ${ }^{26}$ In a setting where the supply of basic donor testing kits are frequently erratic and advanced screening using individual donor nucleic acid amplification is unavailable in many blood banks, transfusion safety in Sub Saharan Africa cannot be guaranteed in the face of a high burden of HBV among blood donors. ${ }^{5}$ Therefore, vaccination against HBV offers a cost-effective means of narrowing the existing gap in transfusion safety while availing an increased number of voluntary blood donors for retention. ${ }^{27,28,29}$ The lifetime cost of managing a patient with chronic hepatitis B, liver cirrhosis, and HBV-induced hepatocellular carcinoma cannot be compared to the cost of three doses of highly effective HBV vaccine. ${ }^{30,31}$ It is hoped that the negative factors affecting enhanced vaccine uptake among blood donors and, by extension, the general population identified in this study will attract the required attention of the policymakers and appropriately addressed to tackle the menace of HBV in our society. Universal HBV vaccine coverage in Nigeria is possible; the right political will and appropriate legislations are needed to actualize it.

\section{CONCLUSION}

Our study found a low uptake of HBV vaccine among blood donors in our environment. Insufficient knowledge about the existence of the vaccine and where it can be accessed were some of the identified factors limiting vaccine uptake in the majority of the subjects. We advocate for increased awareness at governmental and non-governmental fora and the enactment of strong legislation that will ensure universal access to the vaccine by Nigerians.

\section{Limitations}

Our study relied on self-reported hepatitis B vaccination by subjects. It did not confirm their seroconversion status, which could have allowed us to assess vaccine efficacy or failure.

\section{Financial sponsorship: Nil}

Conflict of interests: None declared

\section{REFERENCES}

1. Kaur P, Basu S. Transfusion-transmitted infections: existing and emerging pathogens. Journal of postgraduate medicine. 2005; 51:14651. PMID: 16006714.

2. Olotu AA, Oyelese AO, Salawu L, Audu RA, Okwuraiwe AP, Aboderin AO. Occult Hepatitis B virus infection in previously screened, blood donors in Ile-Ife, Nigeria: implications for blood transfusion and stem cell transplantation. Virology journal. 2016; 13:1-8. DOI:10.1186\%2Fs12985-016-0533-3

3. Li TY, Yang Y, Zhou G, Tu ZK. Immune suppression in chronic hepatitis B infection associated liver disease: A review. World J Gastroenterol. 2019; 25:3527-3537. DOI: 10.3748/wjg.v25.i27.3527.

4. Song CI, Lv J, Liu Y, Chen JG, Ge Z, Zhu J, et 
al. Associations between Bepatitis B Virus Infection and Risk of All Cancer Types. JAMA Netw Open. 2019; 2:e195718.

DOI:10.1001/jamanetworkopen.2019.5718

5. Jefferies M, Rauff B, Rashid H, Lam T, Rafiq S. Update on global epidemiology of viral hepatitis and preventive strategies. World J Clin Cases. 2018; 6:589-599. DOI:10.12998/wjcc. v6.i13.589.

6. Damulak DO, Ogbenna AA, Adediran AO, Samuel E, Rufai O, Bolorunduro SA, et al. The pattern of blood donation and transfusion transmissible infections in the National Blood Transfusion Service in north central Nigeria. Highland Medical Research Journal. 2014; 14:80-84.

7. Uneke CJ, Ogbu O, Inyama PU, Anyanwu GI, Njoku MO, Idoko JH. Prevalence of hepatitis-B surface antigen among blood donors and human immunodeficiency virus-infected patients in Jos, Nigeria. Memórias do Instituto Oswaldo Cruz. 2005; 100:13-6. DOI:10.1590/s007402762005000100002

8. Buseri FI, Muhibi MA, Jeremiah ZA. Seroepidemiology of transfusion-transmissible infectious diseases among blood donors in Osogbo, south-west Nigeria. Blood Transfusion. 2009; 7:293-299. DOI: 10.2450/2009.0071-08.

9. Allain JP, Candotti D, Soldan K, Sarkodie F, Phelps B, Giachetti C, et al. The risk of hepatitis $B$ virus infection by transfusion in Kumasi, Ghana. Blood, The Journal of the American Society of Hematology. 2003; 101:2419-25. DOI:10.1182/blood-2002-04-1084

10. Kim MJ, Park Q, Min HK, Kim HO. Residual risk of transfusion-transmitted infection with human immunodeficiency virus, hepatitis C virus, and hepatitis B virus in Korea from 2000 through 2010. BMC Infect Dis. 2012; 12, 160. DOI:10.1186/1471-2334-12-160

11. Bonsu A, Kwabena-Adu D, Obeng-Ofuri D.
Utilization of Hepatitis B Vaccine among Blood Donors in the Kintampo North Municipal. International Journal of Multidisciplinary Studies and Innovative Research. 2021; 4:37-51http: DOI: 10.21681/IJMSIR-052301-16348-2021

12. Abdo AE, Mohammed DA, Satti M. Prevalence of Hepatitis B virus among blood donors and assessment of blood donor's knowledge about HBV in Sudan. HIV/AIDS Res Treat Open J. 2015; 2:76-80. DOI: 10.17140/HARTOJ-2-112

13. El-Ghitany EM, Farghaly AG. Serological pattern of hepatitis B virus among Hbsag negative blood donors in Alexandria, Egypt. East Mediterr Health J. 2013; 19:600-7. PMID: 24975302.

14. Aroke D, Kadia BM, Anutebeh EN, Belanquale CA, Misori GM, Awa A, et al. Awareness and vaccine coverage of hepatitis $B$ among Cameroonian medical students. BioMed research international. 2018; 2018: 3673289.

DOI: $10.1155 / 2018 / 3673289$

15. Wibabara Y, Banura C, Kalyango J, Karamagi C, Kityamuwesi A, Amia WC, et al. Hepatitis B vaccination status and associated factors among undergraduate students of Makerere University College of Health Sciences. PloS one. 2019; 14:e0214732.

DOI:10.1371/journal.pone.0214732

16. Osei E, Niyilapah J, Kofi Amenuvegbe G. Hepatitis B knowledge, testing, and vaccination history among undergraduate public health students in Ghana. BioMed research international. 2019; 2019: 7645106. DOI:10.1155/2019/7645106

17. Aaron, D., Nagu, T.J., Rwegasha, J., et al. Hepatitis $B$ vaccination coverage among healthcare workers at national hospital in Tanzania: how much, who and why? BMC Infect Dis. 2017; 17: 786. DOI:10.1186/s12879-0172893-8

18. Biset Ayalew M, Adugna Horsa B. Hepatitis B Vaccination Status among Health Care Workers 
in a Tertiary Hospital in Ethiopia. Hepat Res Treat. 2017; 2017:6470658. DOI: $10.1155 / 2017 / 6470658$.

19. Omotowo, I.B., Meka, I.A., Ijoma, U.N., et al. Uptake of hepatitis B vaccination and its determinants among health care workers in a tertiary health facility in Enugu, South-East, Nigeria. BMC Infect Dis. 2018; 18: 288. DOI:10.1186/s12879-018-3191-9

20. Rapisarda V, Nunnari G, Senia P, Vella F, Vitale E, Murabito P, et al. Hepatitis B vaccination coverage among medical residents from Catania University Hospital, Italy. Future microbiology. 2019; 14:41-4. DOI:10.2217/fmb-2018-0240

21. Baldolli A, Michon J, Verdon R, Fournier A. Vaccination perception and coverage among healthcare students in France in 2019. BMC medical education. 2020; 20:1-10. DOI:10.1186/s12909-020-02426-5

22. Ophori EA, Tula MY, Azih AV, Okojie R, Ikpo PE. Current trends of immunization in Nigeria: prospect and challenges. Tropical medicine and health. 2014; 42:67-75. DOI:10.2149/tmh.2013$\underline{13}$

23. World Health Organization: Hepatitis B. Available at: https://www.who.int/newsroom/fact-sheets/detail/hepatitis-b. Updated on $27^{\text {th }}$ July 2020. Accessed on $3^{\text {rd }}$ May 2021.

24. Adedokun, S.T., Uthman, O.A. Women who have not utilized health Service for Delivery in Nigeria: who are they and where do they live? BMC Pregnancy Childbirth. 2019; 19:93. DOI:10.1186/s12884-019-2242-6

25. Klein AA, Arnold P, Bingham RM, Brohi K, Clark R, Collis R, et al. AAGBI guidelines: the use of blood components and their alternatives 2016. Anaesthesia. 2016; 71:829-42.

DOI:10.1111/anae.13489

26. Basu D, Kulkarni R. Overview of blood components and their preparation. Indian $\mathrm{J}$ Anaesth. 2014; 58:529-37. DOI: 10.4103/0019-
5049.144647.

27. Gärtner BC. Vaccination of blood donors against hepatitis B is feasible, safe and cost-effective. Future Virology. 2011; 6:1139-41. DOI: $10.2217 / f v l .11 .86$

28. Zadsar M, Moghaddam ES, Alavian SM, Seighali F. Accelerated hepatitis B vaccination: Efficacy in young, regular blood donors. Glob J Transfus Med. 2020; 5:135-8. DOI:10.4103/GJTM.GJTM_46_19

29. Gerlich WH, Glebe D, Schüttler CG. Hepatitis B viral safety of blood donations: new gaps identified. Ann blood. 2018;3 (0). DOI: 10.21037/aob.2018.09.03

30. Harinder S Chahal, Marion G Peters, Aaron M Harris, Devon McCabe, Paul Volberding, James G Kahn. Cost-effectiveness of Hepatitis B Virus Infection Screening and Treatment or Vaccination in 6 High-risk Populations in the United States. Open Forum Infectious Diseases. 2019; 6:ofy353, DOI:10.1093/ofid/ofy353

31. Mei-Hwei Chang, San-Lin You, Chien-Jen Chen, Chun-Jen Liu, Chuan-Mo Lee, Shi-Ming Lin, et al. The Taiwan Hepatoma Study Group, Decreased Incidence of Hepatocellular Carcinoma in Hepatitis B Vaccinees: A 20-Year Follow-up Study, JNCI: Journal of the National Cancer Institute. 2009; 101:1348-1355. DOI:10.1093/jnci/djp288 